\title{
MEMBANGUN SISTEM INFORMASI PERMINTAAN KANTONG DARAH UTD PMI SUMBAWA BERBASIS $W E B$
}

\author{
Reza Handika Supriatna ${ }^{1}$, Saiful Khair ${ }^{2}$, Yudi Mulyanto ${ }^{3}$ \\ 1,2,3 Program Studi Teknik Informatika, Fakultas Teknologi Informatika, Universitas Teknologi Sumbawa \\ luhaaang@gmail.com ${ }^{1}$,saif.ipb.math@gmail.com², mulyanto.yudi@gmail.com³
}

\begin{abstract}
ABSTRAK
Unit Transfusi Darah (UTD) Kabupaten Sumbawa adalah unit layanan teknis yang berbasis di bawah Palang Merah Indonesia (PMI). UTD PMI Kabupaten Sumbawa memiliki tugas pokok pengorganisasian berupa kegiatan transfusi darah seperti penyebaran darah donor, pengambilan, retensi, pengolahan, penyimpanan dan pengiriman darah ke pasien. Dengan fungsi pelaksanaan pemberian darah transfusi yang aman, efektif, kualitas dalam jumlah cukup, tepat waktu dan mudah memperoleh. Untuk mendapatkan darah dari UTD PMI pasien harus mendapat rekomendasi dari dokter yang merawatnya yang kemudian diserahkan ke petugas UTD PMI untuk melihat darah yang sesuai. Proses ini masih dilakukan secara manual oleh pihak UTD PMI sehingga petugas kesulitan mendata permintaan kantong darah dan kesulitan mendata stok darah yang tersedia. Sistem Informasi Permintaan Kantong Darah UTD PMI Kabupaten Sumbawa berbasis web dirancang untuk membuatnya lebih mudah bagi petugas dalam mendata permintaan darah serta dapat mengetahui stok darah yang tersedia. Perancangan sistem informasi ini menggunakan bahasa pemrograman Hypertext Preprocessor (PHP), pengelola database MySQL, dan metode pengembangan sistem yang digunakan adalah metode waterfall. Hasil dari penelitian ini adalah sistem informasi permintaan kantong darah yang memudahkan petugas dalam mengelola data-data serta data laporan permintaan darah dan stok darah per tahun.
\end{abstract}

Kata Kunci : sistem informasi, web, UTD PMI, darah, teknologi.

\section{PENDAHULUAN}

Palang Merah Indonesia (PMI) merupakan sebuah lembaga yang memiliki jaringan dengan Palang Merah Internasional, yang bekerja sama dengan pemerintah dalam kegiatan sosial seperti penanggulangan bencana, kegiatan donor darah, dan kegiatan kesehatan lainnya di seluruh Indonesia. Pada tataran instansi PMI terutama pada bagian Unit Transfusi Darah (UTD) seperti yang tercantum dalam Peraturan Pemerintah Nomor 7 Tahun 2011, PMI bergerak dalam bidang pencarian, pendataan, melakukan kegiatan meliputi usaha kesehatan. UTD PMI Sumbawa merupakan suatu instansi yang bergerak di bidang kemanusiaan dan merupakan unit cabang PMI di Kabupaten Sumbawa bagian donor darah. Namun UTD PMI Sumbawa dalam kegiatan manajemen pendonoran darah, proses pengolahan data, pencarian data dan pembuatan laporan masih tidak adanya sistem penyimpanan arsip yang cukup memadai yaitu menggunakan buku-buku menyebabkan karyawan administrasi mengalami kesulitan dalam menyajikan data-data permintaan darah dari rumah sakit serta stok kantong darah yang tersedia di UTD PMI. Untuk itu dibutuhkan adanya sistem informasi yang bisa membantu dalam kegiatan operasionalnya agar dalam melaksanakan kegiatannya dapat berjalan secara efektif \& efisien [1].

Berdasarkan masalah di atas, penulis mencoba merancang dan membangun Sistem Informasi Permintaan Kantong Darah UTD PMI Sumbawa berbasis web, sebuah sistem yang dapat membantu karyawan dalam mengelola data-data permintaan darah yang terekam dalam sistem.

\section{METODOLOGI}

Metode yang digunakan dalam penelitian ini adalah waterfall yang terdiri dari lima tahapan yaitu [2]:

\section{Analisis Kebutuhan}

Analisa kebutuhan merupakan tahapan awal yang dilakukan oleh penulis. 
Dalam tahapan ini penulis menganalisa kebutuhan admin, kebutuhan perangkat lunak dan kebutuhan perangkat keras. Hasil analisa didapatkan dari pengumpulan data yang dilakukan terlebih dahulu yaitu dengan cara wawancara dan studi pustaka.

\section{Desain Sistem}

Desain sistem merupakan langkah merancang sistem yang akan dibangun. Perancangan sistem ini meliputi perancangan sistem, perancangan basis data, serta perancangan user interface yang menggambarkan desain umum dari sistem yang dibangun.

\section{Penulisan Kode Program}

Dalam tahapan ini penulis menerjemahkan desain sistem yang telah dirancang sebelumnya ke dalam bahasa pemrograman PHP dan MySQL sebagai sistem manajemen basis data.

\section{Pengujian Program}

Tahapan pengujian program adalah tahapan sistem yang telah dibangun akan di uji. Tujuan dari pengujian ini adalah menemukan apakah terdapat galat (error) dalam sistem serta menguji kinerja sistem apakah sudah berjalan sesuai dengan yang diharapkan.

\section{Penerapan Program}

Setelah melakukan pengujian, sistem yang telah dibangun akan mulai diterapkan pada UTD PMI Sumbawa. Penerapan dan pengoperasian sistem yang dibuat untuk menggantikan sistem yang sebelumnya menggunakan sistem manual dengan menggunakan buku menjadi sistem informasi komputasi yang membantu mengelola data permintaan kantong darah.

\section{HASIL DAN PEMBAHASAN}

Dengan berdasarkan metode Waterfall yang digunakan dalam penelitian ini, maka proses yang dilakukan dalam membangun Sistem Informasi Permintaan Kantong Darah UTD PMI Kabupaten Sumbawa Berbasis Web adalah sebagai berikut:

\section{Analisis Kebutuhan}

Dalam tahapan ini peneliti mendapatkan data dan informasi yang dibutuhkan. Teknik pengumpulan data merupakan langkah yang paling strategis dalam penelitian, karena tujuan utama dari penelitian adalah mendapatkan data. Salah satunya adalah dengan melakukan wawancara, yang merupakan pertemuan dua orang untuk bertukar informasi dan ide melalui tanya jawab, sehingga dapat dikontruksikan makna dalam suatu topik tertentu [3]. Dalam hal ini peneliti melakukan wawancara dengan pihak UTD PMI Kabupaten Sumbawa. Berikut adalah hasil analisis kebutuhan:

a. Kebutuhan admin

Adapun kebutuhan admin dalam pembangunan sistem informasi permintaan kantong darah ini adalah:

- Admin dapat melakukan penyimpanan data permintaan kantong darah dan stok darah.

- Admin dapat melakukan pembaharuan data stok darah.

- Admin dapat melakukan pencarian data permintaan darah dan stok darah.

- Admin bisa menghasilkan keluaran berupa laporan data permintaan darah dan stok darah dalam periode tertentu.

b. Kebutuhan Perangkat Keras

Kebutuhan minimum perangkat keras yang digunakan dalam sistem informasi permintaan kantong darah ini adalah:

Tabel 1. Kebutuhan Perangkat Keras

\begin{tabular}{|l|l|}
\hline \multicolumn{1}{|c|}{ Perangkat Keras } & \multicolumn{1}{c|}{ Keterangan } \\
\hline Processor & $1.5 \mathrm{GHz}$ \\
\hline RAM & $512 \mathrm{MB}$ \\
\hline Resolusi Monitor & $1024 \times 768$ \\
\hline Storage & $100 \mathrm{MB}$ tersedia \\
\hline
\end{tabular}

c. Kebutuhan Perangkat Lunak

Kebutuhan perangkat lunak yang digunakan untuk sistem informasi permintaan kantong ini adalah:

Tabel 2. Kebutuhan Perangkat Lunak

\begin{tabular}{|l|l|}
\hline \multicolumn{1}{|c|}{ Perangkat Lunak } & \multicolumn{1}{c|}{ Keterangan } \\
\hline Sistem Operasi & Windows XP Pro \\
\hline Web Server & XAMPP versi 3.2.2 \\
\hline Database & MySQL versi 5.6.20 \\
\hline Development Tool & PHP versi 5.5.15 \\
\hline
\end{tabular}




\section{Desain Sistem}

Dalam proses perancangan sistem, di mana bertujuan untuk memberikan gambaran tentang sistem yang akan di bangun dan tampilan dari sistem. Tahap membantu peneliti dalam mendefinisikan arsitektur sistem secara keseluruhan.

\section{Diagram Konteks}

Diagram konteks merupakan diagram yang terdiri dari suatu proses dan menggambarkan ruang lingkup dari secara umum dari sistem yang dibuat yaitu Sistem Informasi Permintaan Kantong Darah di UTD PMI Kabupaten Sumbawa. Diagram konteks merupakan level tertinggi dari DFD yang menggambarkan seluruh input atau output dari sistem yang memberi gambaran tentang keseluruhan dari sistem. Berikut adalah diagram konteks dari Sistem Informasi Permintaan Kantong Darah di UTD PMI Kabupaten Sumbawa.

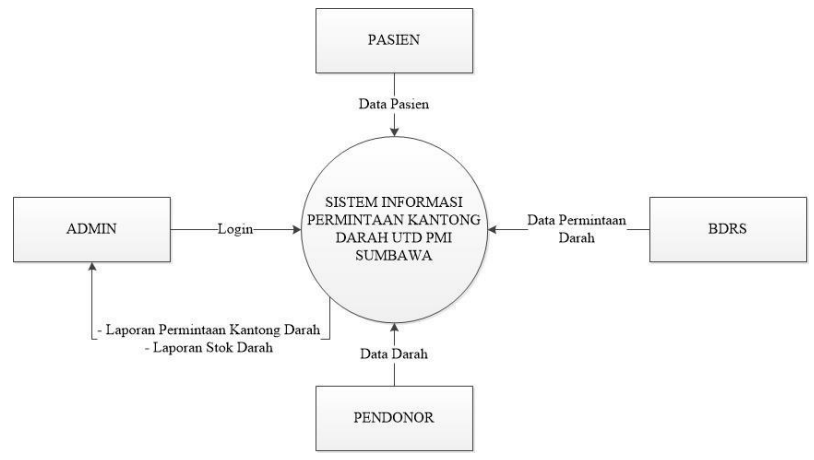

Gambar 1. Diagram Konteks Data Flow Diagram (DFD)

DFD adalah suatu diagram yang menggunakan notasi-notasi untuk menggambarkan arus dari data sistem, yang penggunaannya sangat membantu untuk memahami sistem secara logika, tersruktur dan jelas [4]. DFD merupakan alat bantu dalam menggambarkan atau menjelaskan sistem yang sedang berjalan logis.

DFD level 0 menggambarkan semua alur kerja proses pengolahan data pada halaman administrator yang merupakan pejabaran lebih rinci dari proses diagram konteks, yang terdiri dari proses pendataan permintaan kantong darah, penerimaan dan pengeluaran kantong darah, stok darah, serta pencetakan laporan.

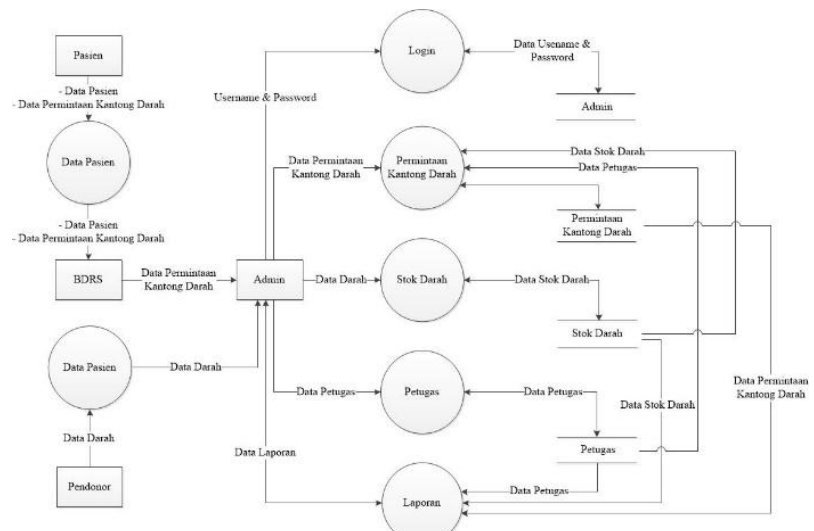

Gambar 2. DFD level 0

\section{Entity Relationship Diagram (ERD)}

Entity Relationship Diagram merupakan hubungan antara entitasentitas yang terdapat dalam Sistem Informasi Permintaan Kantong Darah UTD PMI Kabupaten Sumbawa. Berikut adalah ERD yang terdapat dalam Sistem Informasi Permintaan Kantong Darah UTD PMI Kabupaten Sumbawa.

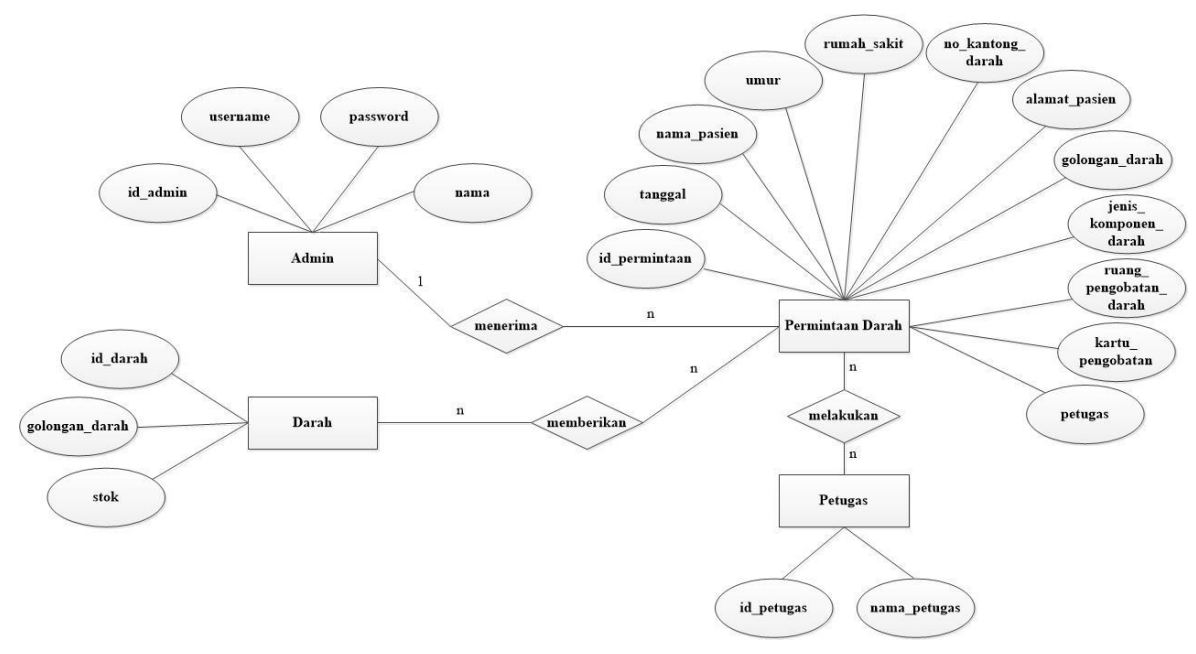




\section{Gambar 3. Entity Relationship Diagram}

\section{Rancangan Struktur Database}

Dalam perancangan struktur database Sistem Informasi Permintaan Kantong Darah UTD PMI Sumbawa dibutuhkan beberapa tabel yaitu tabel admin, permintaan_darah, stok_darah, darah, dan petugas.

a. Tabel admin

Nama tabel : admin

Keterangan : Tabel admin digunakan untuk menyimpan data admin yang mengelola sistem. Berikut struktur tabel admin.

Tabel 3. Tabel admin

\begin{tabular}{|c|l|c|c|c|}
\hline No & \multicolumn{1}{|c|}{ Field } & Type & Length & Extra \\
\hline 1 & id_admin & int & 3 & Primary Key \\
\hline 2 & username & varchar & 20 & \\
\hline 3 & password & varchar & 50 & \\
\hline 4 & nama & varchar & 50 & \\
\hline
\end{tabular}

b. Tabel permintaan_darah Nama tabel : permintaan_darah Keterangan : Tabel permintaan darah digunakan untuk menyimpan data permintaan kantong darah. Berikut merupakan struktur tabel permintaan darah.

Tabel 4. Tabel permintaan_darah

\begin{tabular}{|c|c|c|c|c|}
\hline No & Field & Type & Length & Extra \\
\hline 1 & id_permintaan & int & 3 & Primary Key \\
\hline 2 & tanggal & date & & \\
\hline 3 & nama_pasien & varchar & 50 & \\
\hline 4 & umur & int & 3 & \\
\hline 5 & rumah_sakit & int & 1 & \\
\hline 6 & $\begin{array}{l}\text { no_kantong_da } \\
\text { rah }\end{array}$ & char & 8 & \\
\hline 7 & alamat_pasien & text & & \\
\hline 8 & $\begin{array}{l}\text { golongan_dara } \\
\mathrm{h}\end{array}$ & int & 11 & \\
\hline 9 & $\begin{array}{l}\text { jenis_kompone } \\
\text { n_darah }\end{array}$ & varchar & 20 & \\
\hline 10 & $\begin{array}{l}\text { ruang_pengob } \\
\text { atan_pasien }\end{array}$ & varchar & 20 & \\
\hline 11 & $\begin{array}{l}\text { kartu_pengoba } \\
\tan \end{array}$ & varchar & 20 & \\
\hline 12 & petugas & int & 11 & \\
\hline
\end{tabular}

c. Tabel darah Nama tabel : darah Keterangan : Tabel darah digunakan untuk menyimpan data darah serta stok darah yang tersedia. Berikut merupakan struktur tabel darah.

Tabel 5. Tabel darah

\begin{tabular}{|c|l|c|c|c|}
\hline No & \multicolumn{1}{|c|}{ Field } & Type & Length & Extra \\
\hline 1 & id_darah & int & 3 & Primary Key \\
\hline 2 & $\begin{array}{l}\text { golongan_dara } \\
\text { h }\end{array}$ & varchar & 5 & \\
\hline 3 & stok & int & 11 & \\
\hline
\end{tabular}

d. Tabel petugas

Nama tabel : petugas

Keterangan: Tabel petugas digunakan untuk menyimpan data petugas yang mengurusi kegiatan permintaan darah. Berikut merupakan struktur tabel petugas.

Tabel 6. Tabel petugas

\begin{tabular}{|c|l|c|c|c|}
\hline No & Field & Type & Length & Extra \\
\hline 1 & id_petugas & int & 3 & Primary Key \\
\hline 2 & nama_petugas & varchar & 50 & \\
\hline
\end{tabular}

\section{Perancangan Antar Muka (User Interface)}

Rancangan user interface merupakan rancangan tampilan antarmuka dari sistem yang akan dibangun. Berikut merupakan rancangan user interface dari Sistem Informasi Permintaan Kantong Darah UTD PMI Kabupaten Sumbawa.

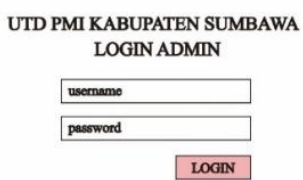

Gambar 4. Rancangan tampilan login admin

a. Rancangan Tampilan Login Admin Dalam tampilan rancangan login admin terdapat dua form yaitu form username dan form password yang harus diisi agar dapat masuk ke dalam sistem.

b. Rancangan tampilan dashboard 


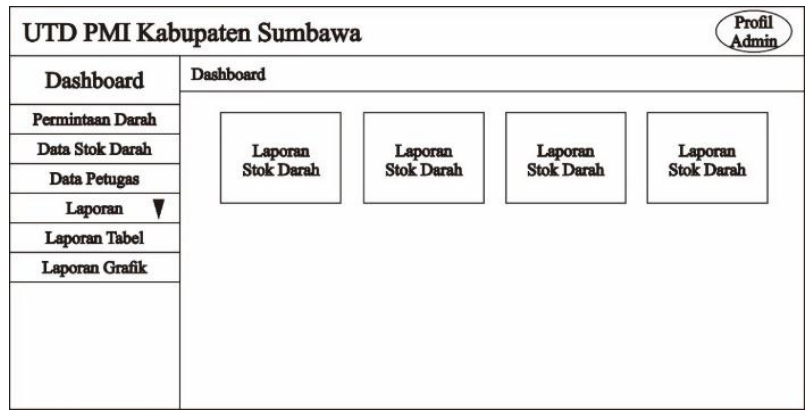

Gambar 5. Rancangan tampilan dashboard

Rancangan tampilan dashboard merupakan halaman pertama yang ditampilkan kepada admin ketika berhasil masuk ke sistem. Pada halaman dashboard menampilkan menu-menu untuk dapat mengelola data-data permintaan kantong darah.

c. Rancangan tampilan menu permintaan darah

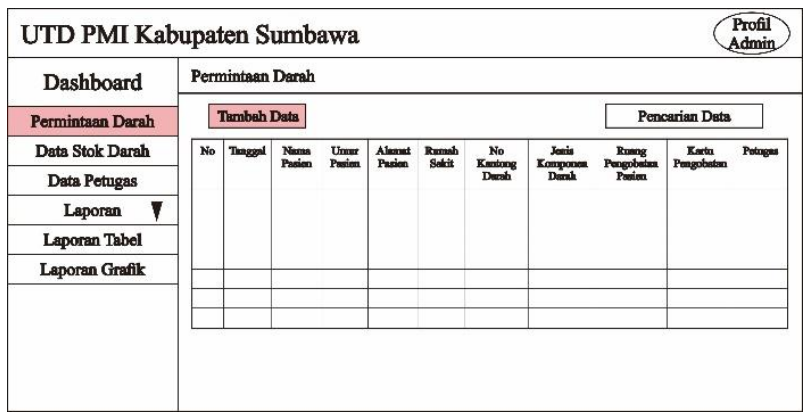

Gambar 6. Rancangan tampilan menu permintaan darah

Rancangan tampilan menu permintaan darah akan menampilkan data-data dari permintaan darah dari pasien.

d. Rancangan tampilan tambah data

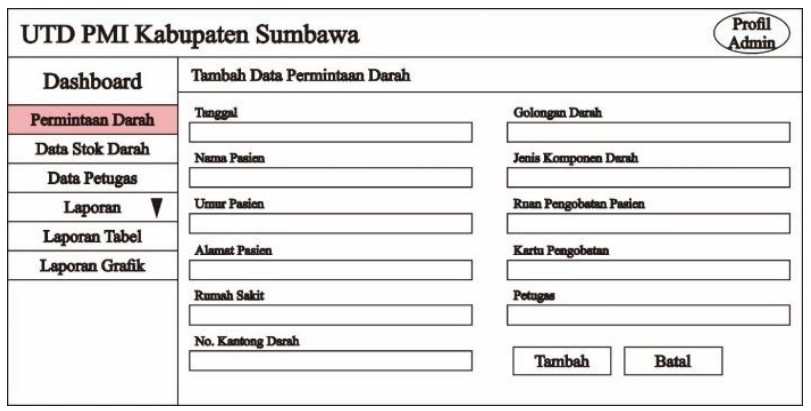

Gambar 7. Rancangan tampilan tambah data
Dalam rancangan tampilan tambah data permintaan darah akan menampilkan beberapa form yang akan diisi oleh admin untuk menambahkan permintaan darah baru.

e. Rancangan tampilan laporan

\begin{tabular}{|c|c|c|c|}
\hline \multicolumn{2}{|c|}{ UTD PMI Kabupaten Sumbawa } & & $\begin{array}{l}\text { Profil } \\
\text { Admii }\end{array}$ \\
\hline Dashboard & \multicolumn{3}{|l|}{ Permintaan Darah } \\
\hline Permintaan Darah & & Pencerimn Data & \begin{tabular}{|l|} 
Cotak ke Breel \\
\end{tabular} \\
\hline Data Stok Darah & & & \\
\hline \multicolumn{4}{|l|}{ Data Petugas } \\
\hline \multicolumn{4}{|l|}{ Laporan V } \\
\hline \multirow{2}{*}{\multicolumn{4}{|c|}{$\begin{array}{l}\text { Laporan Tabel } \\
\text { Laporan Grafik } \\
\end{array}$}} \\
\hline & & & \\
\hline & & & \\
\hline & & & \\
\hline
\end{tabular}

\section{Gambar 8. Rancangan tampilan laporan tabel}

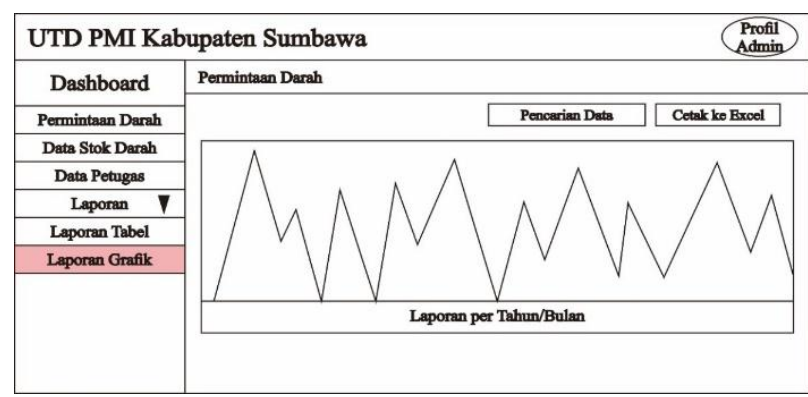

Gambar 9. Rancangan tampilan laporan grafik

Rancangan tampilan menu laporan akan menampilkan laporan dari transaksi darah yang dilakukan seperti pemasukan stok darah, pengeluaran kantong darah, stok darah yang tersedia per bulan atau per tahun dalam bentuk tabel dan grafik.

\section{Penulisan Kode Program}

Dalam tahapan ini desain-desain dari perancangan sistem yang akan di bangun mulai di implementasikan ke dalam bahasa pemrograman. Proses implementasi di mulai dari pembangunan database pada basis data MySQL dengan menggunakan XAMPP. Kemudian proses pengkodean dibantu dengan bahasa pemrograman PHP (Hypertext Preprocessor) dan web editor menggunakan aplikasi Brackets.

\section{Pengujian Program}


Dalam tahapan ini sistem akan diuji setelah pengkodean selesai dikerjakan. Pengujian dilakukan dengan terlebih dahulu melakukan proses mengimplementasian aplikasi, yaitu:

a. Implementasi Halaman Login Admin

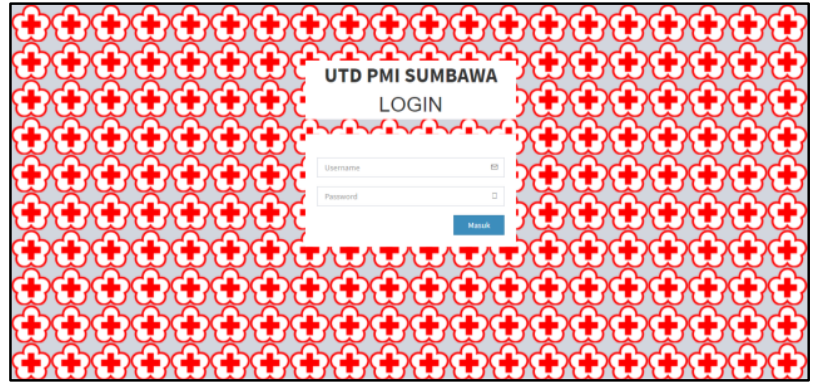

Gambar 10. Implementasi Halaman Login Admin

Halaman login adalah halaman pertama kali tampil ketika sistem pertama kali dibuka. Halaman ini terdapat dua form yaitu username dengan password agar dapat mengakses sistem.

\section{b. Implementasi Halaman Dashboard}

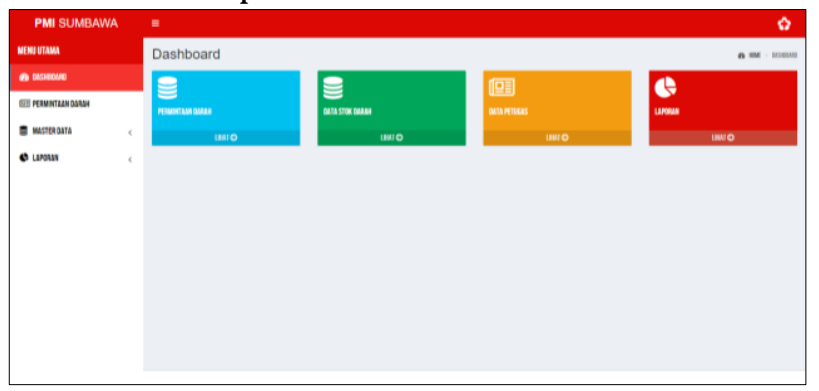

Gambar 11. Implementasi Halaman Dashboard

Setelah admin berhasil masuk ke sistem, admin akan masuk ke tampilan dashboard. Dalam dashboard admin dapat mengakses sistem dengan memilih menu seperti dashboard, permintaan darah, master data yang terdiri dari data petugas dan data stok darah, serta laporan yang terdiri dari laporan bentuk tabel dan grafik.

c. Implementasi Halaman Menu Permintaan Darah

d. Dalam menu permintaan darah akan menampilkan data-data permintaan darah dalam bentuk tabel, tombol tambah data untuk menambah data permintaan darah yang baru, serta form pencarian data berdasarkan tahun dan tombol cetak untuk mencetak data dalam bentuk format Microsoft Excel.

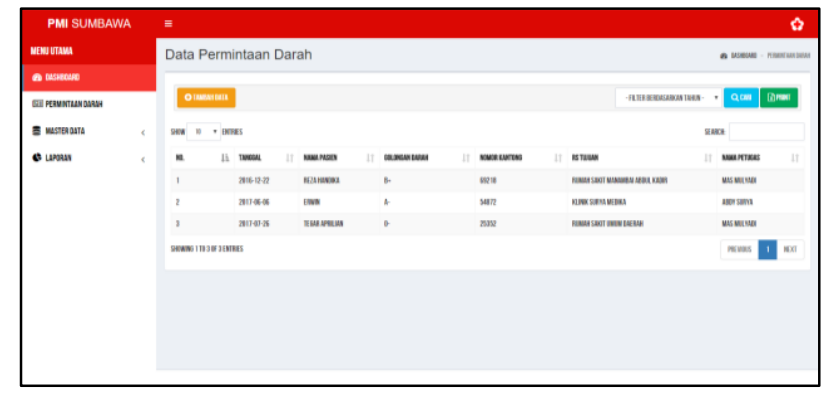

Gambar 12. Implementasi Halaman Menu Permintaan Darah

e. Implementasi Halaman Tambah Data Permintaan Darah

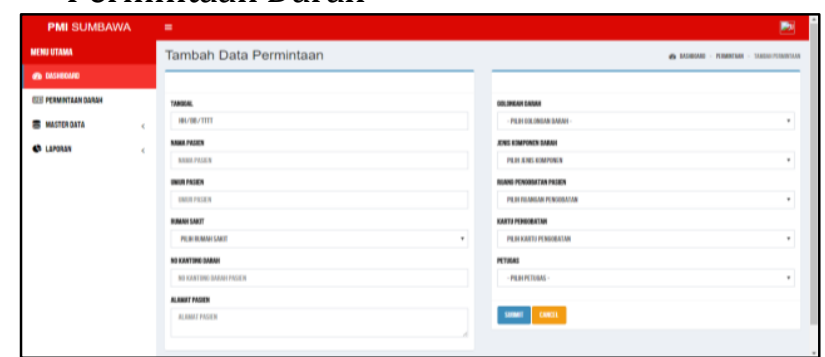

Gambar 13. Implementasi Halaman Tambah Data Permintaan Darah

Dalam tampilan tambah data permintaan darah akan menampilkan form-form inputan yang diisi seperti tanggal, nama pasien, umur pasien, rumah sakit, nomor kantong darah, alamat pasien, golongan darah, jenis komponen darah, ruang pengobatan pasien, kartu pengobatan serta petugas.

f. Implementasi Halaman Laporan

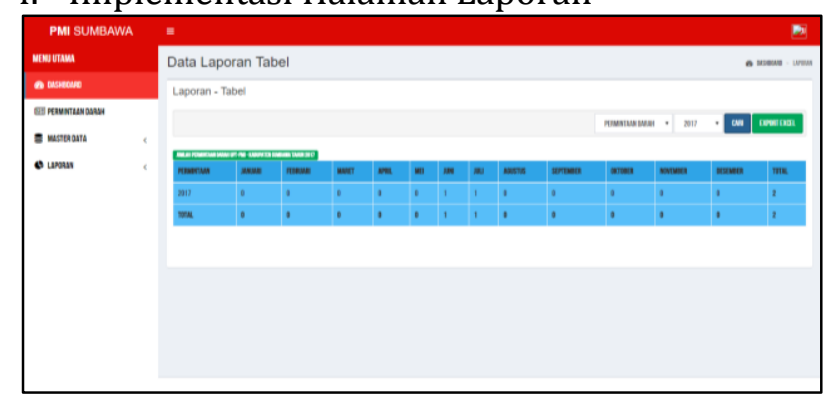

Gambar 14. Implementasi Halaman Laporan Tabel 


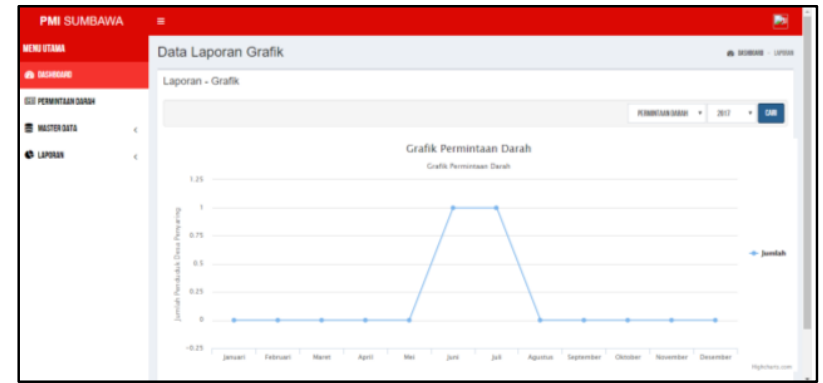

Gambar 15. Implementasi Halaman Laporan Grafik

Dalam tampilan laporan akan menampilkan laporan permintaan darah serta stok darah dalam bentuk tabel dan grafik, pencarian data berdasarkan tahun serta mencetak laporan dalam bentuk format Microsoft Excel.

Proses pengujian aplikasi telah dilakukan adalah dengan Black Box Testing, merupakan pengujian yang berfokus pada spesifikasi fungsional dari perangkat lunak, penguji dapat mendefinisikan kumpulan kondisi input dan melakukan pengetesan pada spesifikasi fungsional program [5].

Hasil dari pengujian yang dilakukan adalah sebagai berikut:

\section{Rencana Pengujian}

\section{Tabel 7. Rencana Pengujian}

\begin{tabular}{|c|c|c|}
\hline Kelas Uji & Butir Uji & $\begin{array}{c}\text { Jenis } \\
\text { Pengujian }\end{array}$ \\
\hline Login & $\begin{array}{l}\text { Verifikasi } \\
\text { username dan } \\
\text { password }\end{array}$ & Black Box \\
\hline \multirow{3}{*}{$\begin{array}{l}\text { Pengolahan } \\
\text { Data } \\
\text { Permintaan } \\
\text { Kantong } \\
\text { Darah }\end{array}$} & Tambah Data & Black Box \\
\hline & $\begin{array}{l}\text { Pencarian } \\
\text { Data }\end{array}$ & Black Box \\
\hline & $\begin{array}{l}\text { Mencetak } \\
\text { Laporan }\end{array}$ & Black Box \\
\hline \multirow{3}{*}{$\begin{array}{l}\text { Pengolahan } \\
\text { Laporan }\end{array}$} & $\begin{array}{l}\text { Menampilkan } \\
\text { Laporan } \\
\text { dalam Bentuk } \\
\text { Tabel }\end{array}$ & Black Box \\
\hline & $\begin{array}{l}\text { Menampilkan } \\
\text { Laporan } \\
\text { dalam Bentuk } \\
\text { Grafik }\end{array}$ & Black Box \\
\hline & $\begin{array}{l}\text { Mencetak } \\
\text { Laporan }\end{array}$ & Black Box \\
\hline
\end{tabular}

a. Pengujian Login

Berikut ini adalah hasil pengujian login untuk memverifikasi username dan password: 
JURNAL TAMBORA Vol 2 No 2 Agustus 2017

Tabel 8. Pengujian Login

\begin{tabular}{|c|c|c|c|}
\hline \multicolumn{4}{|c|}{ Hasil Uji (Data Normal) } \\
\hline Data Masukan & Yang Diharapkan & Pengamatan & Kesimpulan \\
\hline $\begin{array}{l}\text { Username: admin, } \\
\text { password: admin. }\end{array}$ & $\begin{array}{l}\text { admin tercantum pada } \\
\text { username, admin } \\
\text { tercantum pada } \\
\text { password }\end{array}$ & $\begin{array}{l}\text { admin tercantum pada } \\
\text { username, } * * * * \\
\text { tercantum pada } \\
\text { password }\end{array}$ & Berhasil \\
\hline Tombol login & $\begin{array}{l}\text { Data username } \\
\text { diterima, masuk ke } \\
\text { dashboard. }\end{array}$ & $\begin{array}{l}\text { Tombol login } \\
\text { berfungsi dan berhasil } \\
\text { login. }\end{array}$ & Berhasil \\
\hline \multicolumn{4}{|c|}{ Hasil Uji (Data Salah) } \\
\hline Data Masukan & Yang Diharapkan & Pengamatan & Kesimpulan \\
\hline $\begin{array}{l}\text { Username: dicoba, } \\
\text { password: dicoba. }\end{array}$ & $\begin{array}{l}\text { dicoba tercantum } \\
\text { pada username, } \\
\text { dicoba tercantum } \\
\text { pada password }\end{array}$ & $\begin{array}{l}\text { dicoba tercantum } \\
\text { pada username, } * * * * * * \\
\text { tercantum pada } \\
\text { password }\end{array}$ & Berhasil \\
\hline Tombol login & $\begin{array}{l}\text { Data username tidak } \\
\text { ditemukan dalam } \\
\text { database, gagal login } \\
\text { dan menampilkan } \\
\text { pesan error. }\end{array}$ & $\begin{array}{l}\text { Tombol login } \\
\text { berfungsi, gagal login } \\
\text { dan menampilkan } \\
\text { pesan error. }\end{array}$ & Berhasil \\
\hline
\end{tabular}

\section{b. Pengujian Pengolahan Data Perrmintaan Kantong Darah}

Dalam pengujian pengolahan data perrmintaan kantong darah terdiri dari 3 bagian yaitu:

1) Tambah Data

Berikut ini adalah hasil pengujian tambah data dalam pengolahan data perrmintaan kantong darah:

Tabel 9. Tambah Data

\begin{tabular}{|c|c|c|c|}
\hline \multicolumn{4}{|c|}{ Hasil Uji (Data Normal) } \\
\hline Data Masukan & Yang Diharapkan & Pengamatan & Kesimpulan \\
\hline Tombol Tambah & $\begin{array}{l}\text { Muncul form tambah } \\
\text { data }\end{array}$ & $\begin{array}{l}\text { Tampil form tambah } \\
\text { data }\end{array}$ & Berhasil \\
\hline $\begin{array}{l}\text { Tanggal: 15/05/2017, } \\
\text { nama pasien: Edwin } \\
\text { Baskara, umur: 40, } \\
\text { rumah sakit: Klinik } \\
\text { Surya Medika, no } \\
\text { kantong: } 21735, \\
\text { alamat pasien: } \\
\text { Sumbawa, golongan } \\
\text { darah: AB+, jenis } \\
\text { komponen darah: PRC, } \\
\text { ruang pengobatan: } \\
\text { ICU, kartu } \\
\text { pengobatan: BPJS, } \\
\text { petugas: Abdy Surya }\end{array}$ & $\begin{array}{l}\text { Semua data tercantum } \\
\text { dalam form }\end{array}$ & $\begin{array}{l}\text { Dapat mengisi tanggal, } \\
\text { nama pasien, umur, } \\
\text { rumah sakit, no } \\
\text { kantong, alamat } \\
\text { pasien, golongan } \\
\text { darah, jenis komponen } \\
\text { darah, ruang } \\
\text { pengobatan, kartu } \\
\text { pengobatan, dan } \\
\text { petugas. Sesuai yang } \\
\text { diharapkan. }\end{array}$ & Berhasil \\
\hline Klik tombol submit & $\begin{array}{l}\text { Data tersimpan ke } \\
\text { dalam database dan } \\
\text { ditampilkan pada } \\
\text { tabel dalam menu } \\
\text { Permintaan } \\
\end{array}$ & $\begin{array}{l}\text { Data tersimpan dalam } \\
\text { database }\end{array}$ & Berhasil \\
\hline Klik tombol cancel & $\begin{array}{l}\text { Semua data dalam } \\
\text { form terhapus dan } \\
\text { tetap dalam tampilan } \\
\text { form tambah data }\end{array}$ & $\begin{array}{l}\text { Semua data dalam } \\
\text { form terhapus dan } \\
\text { tetap dalam tampilan } \\
\text { form tambah data. }\end{array}$ & Berhasil \\
\hline
\end{tabular}


JURNAL TAMBORA Vol 2 No 2 Agustus 2017

\begin{tabular}{|c|l|l|c|}
\hline & \multicolumn{1}{|c|}{} & $\begin{array}{l}\text { Sesuai dengan yang } \\
\text { diharapkan }\end{array}$ & Kesimpulan \\
\hline \multicolumn{3}{|c|}{ Hasil Uji (Data Salah) } \\
\hline Data Masukan & \multicolumn{1}{|c|}{ Yang Diharapkan } & \multicolumn{1}{|c|}{ Pengamatan } & Berhasil \\
\hline Data tidak diisi & $\begin{array}{l}\text { Data tidak tersimpan } \\
\text { dan menampilkan } \\
\text { pesan kesalahan }\end{array}$ & $\begin{array}{l}\text { Data tidak tersimpan } \\
\text { dan menampilkan } \\
\text { pesan kesalahan } \\
\text { sesuai dengan yang } \\
\text { diharapkan. }\end{array}$ & \\
\hline
\end{tabular}

\section{2) Pencarian Data}

Dalam pencarian data terdapat dua pilihan yaitu pencarian data berdasarkan tahun dan pencarian dengan mengisi form. Berikut ini adalah hasil pengujian pencarian data dalam pengolahan data perrmintaan kantong darah:

\section{Tabel 10. Pencarian data}

\begin{tabular}{|l|l|l|c|}
\hline \multicolumn{5}{|c|}{ Hasil Uji (Data Normal) } \\
\hline Data Masukan & \multicolumn{1}{|c|}{ Yang Diharapkan } & \multicolumn{1}{c|}{ Pengamatan } & Kesimpulan \\
\hline Tombol dropdown & $\begin{array}{l}\text { Menampilkan pilihan } \\
\text { tahun pencarian data }\end{array}$ & $\begin{array}{l}\text { Menampilkan pilihan } \\
\text { tahun pencarian data } \\
\text { sesuai dengan yang } \\
\text { diharapkan }\end{array}$ & Berhasil \\
\hline Tombol cari & $\begin{array}{l}\text { Muncul data } \\
\text { permintaan } \\
\text { berdasarkan tahun }\end{array}$ & $\begin{array}{l}\text { Tampil data } \\
\text { permintaan } \\
\text { berdasarkan tahun }\end{array}$ & Berhasil \\
\hline $\begin{array}{l}\text { Edwin dalam form } \\
\text { pencarian }\end{array}$ & $\begin{array}{l}\text { Data yang dicari } \\
\text { ditemukan dan } \\
\text { ditampilkan secara } \\
\text { langsung }\end{array}$ & $\begin{array}{l}\text { Menampilkan data } \\
\text { yang dicari ditemukan } \\
\text { dan ditampilkan } \\
\text { secara langsung }\end{array}$ & Berhasil \\
\hline \multicolumn{1}{|c|}{ Hasil Uji (Data Salah) } & Kesimpulan \\
\hline Data Masukan & \multicolumn{1}{|c|}{ Pengamatan } \\
Test dalam form \\
pencarian
\end{tabular}

\section{3) Mencetak Laporan}

Berikut ini adalah hasil pengujian mencetak laporan dalam pengolahan data perrmintaan kantong darah:

Tabel 11. Mencetak Laporan

\begin{tabular}{|c|l|l|c|}
\hline \multicolumn{5}{|c|}{ Hasil Uji (Data Normal) } \\
\hline Data Masukan & \multicolumn{1}{|c|}{ Yang Diharapkan } & Pengamatan & Kesimpulan \\
\hline \multirow{4}{*}{ Klik tombol print } & $\begin{array}{l}\text { Data permintaan yang } \\
\text { tersimpan dalam } \\
\text { database dapat di } \\
\text { download dalam } \\
\text { format Excel }\end{array}$ & $\begin{array}{l}\text { Data ter-download } \\
\text { dalam format Excel }\end{array}$ & Berhasil \\
\hline \multicolumn{4}{|c|}{ Hasil Uji (Data Salah) } \\
\hline Data Masukan & Yang Diharapkan & Pengamatan & Kesimpulan \\
\hline- & - & - & - \\
\hline
\end{tabular}

c. Pengujian Pengolahan Laporan

Dalam pengujian pengolahan laporan terdiri dari dua bagian yaitu:

1) Menampilkan laporan dalam bentuk tabel 
Berikut ini adalah hasil pengujian menampilkan laporan dalam bentuk tabel:

Tabel 12. Pengujian menampilkan laporan dalam bentuk tabel

\begin{tabular}{|c|c|c|c|}
\hline \multicolumn{4}{|c|}{ Hasil Uji (Data Normal) } \\
\hline Data Masukan & Yang Diharapkan & Pengamatan & Kesimpulan \\
\hline $\begin{array}{l}\text { Tombol dropdown } \\
\text { filter }\end{array}$ & $\begin{array}{l}\text { Muncul pilihan } \\
\text { laporan yang ingin } \\
\text { ditampilkan }\end{array}$ & $\begin{array}{l}\text { Menampilkan pilihan } \\
\text { laporan permintaan } \\
\text { darah dan stok darah } \\
\text { sesuai dengan yang } \\
\text { diharapkan }\end{array}$ & Berhasil \\
\hline $\begin{array}{l}\text { Tombol dropdown } \\
\text { tahun }\end{array}$ & $\begin{array}{l}\text { Muncul pilihan tahun } \\
\text { yang ingin } \\
\text { ditampilkan }\end{array}$ & $\begin{array}{l}\text { Menampilkan pilihan } \\
\text { tahun permintaan } \\
\text { darah dan stok darah } \\
\text { sesuai dengan yang } \\
\text { diharapkan }\end{array}$ & Berhasil \\
\hline Tombol cari & $\begin{array}{l}\text { Muncul laporan dalam } \\
\text { bentuk tabel } \\
\text { berdasarkan tahun }\end{array}$ & $\begin{array}{l}\text { Menampilkan laporan } \\
\text { dalam bentuk tabel } \\
\text { berdasarkan tahun }\end{array}$ & Berhasil \\
\hline \multicolumn{4}{|c|}{ Hasil Uji (Data Salah) } \\
\hline Data Masukan & Yang Diharapkan & Pengamatan & Kesimpulan \\
\hline Tidak memilih pilihan & $\begin{array}{l}\text { Data yang dicari tidak } \\
\text { ditemukan dan } \\
\text { menampilkan pesan } \\
\text { error }\end{array}$ & $\begin{array}{l}\text { Data yang dicari tidak } \\
\text { ditemukan dan } \\
\text { menampilkan pesan } \\
\text { error sesuai dengan } \\
\text { yang diharapkan }\end{array}$ & Berhasil \\
\hline
\end{tabular}

2) Menampilkan laporan dalam bentuk grafik

Berikut ini adalah hasil pengujian menampilkan laporan dalam bentuk grafik:

Tabel 13. Pengujian menampilkan laporan dalam bentuk grafik

\begin{tabular}{|c|c|c|c|}
\hline \multicolumn{4}{|c|}{ Hasil Uji (Data Normal) } \\
\hline Data Masukan & Yang Diharapkan & Pengamatan & Kesimpulan \\
\hline $\begin{array}{l}\text { Tombol dropdown } \\
\text { filter }\end{array}$ & $\begin{array}{l}\text { Muncul pilihan } \\
\text { laporan yang ingin } \\
\text { ditampilkan }\end{array}$ & $\begin{array}{l}\text { Menampilkan pilihan } \\
\text { laporan permintaan } \\
\text { darah dan stok darah } \\
\text { sesuai dengan yang } \\
\text { diharapkan }\end{array}$ & Berhasil \\
\hline $\begin{array}{l}\text { Tombol dropdown } \\
\text { tahun }\end{array}$ & $\begin{array}{l}\text { Muncul pilihan tahun } \\
\text { yang ingin } \\
\text { ditampilkan }\end{array}$ & $\begin{array}{l}\text { Menampilkan pilihan } \\
\text { tahun permintaan } \\
\text { darah dan stok darah } \\
\text { sesuai dengan yang } \\
\text { diharapkan } \\
\end{array}$ & Berhasil \\
\hline Tombol cari & $\begin{array}{l}\text { Muncul laporan dalam } \\
\text { bentuk grafik } \\
\text { berdasarkan tahun }\end{array}$ & $\begin{array}{l}\text { Menampilkan laporan } \\
\text { dalam bentuk grafik } \\
\text { berdasarkan tahun }\end{array}$ & Berhasil \\
\hline \multicolumn{4}{|c|}{ Hasil Uji (Data Salah) } \\
\hline Data Masukan & Yang Diharapkan & Pengamatan & Kesimpulan \\
\hline Tidak memilih pilihan & $\begin{array}{l}\text { Data yang dicari tidak } \\
\text { ditemukan dan } \\
\text { menampilkan pesan } \\
\text { error }\end{array}$ & $\begin{array}{l}\text { Data yang dicari tidak } \\
\text { ditemukan dan } \\
\text { menampilkan pesan } \\
\text { error sesuai dengan } \\
\text { yang diharapkan }\end{array}$ & Berhasil \\
\hline
\end{tabular}

\section{KESIMPULAN DAN SARAN KESIMPULAN}

Dari hasil analisis dan perancangan sistem yang telah dilakukan oleh penulis, maka dapat diambil kesimpulan bahwa Sistem Informasi Permintaan Kanton Darah UTD PMI Kabupaten Sumbawa 
berbasis web telah selesai dibangun dengan menggunakan bahasa pemrograman PHP, database MySql dan Bootstrap yang dapat digunakan oleh UTD PMI Kabupaten Sumbawa untuk mempermudah petugas dalam mengelola permintaan kantong darah dan pembuatan laporan transaksi kantong darah.

\section{SARAN}

Dari hasil pembangunan Sistem Informasi Permintaan Kanton Darah UTD PMI Kabupaten Sumbawa berbasis web, penulis memberikan saran agar pada tahap selanjutnya dilakukan pengembangan berikutnya yang meliputi:

1. Diintergrasikan dengan website dan mobile android dengan tujuan bisa dipublikasikan ke masyarakat tentang stok darah yang tersedia pada UTD PMI Kabupaten Sumbawa.

2. Penyatuan dengan sistem yang telah ada pada UTD PMI Kabupaten Sumbawa yaitu sistem data pendonor agar sistem yang dibangun menjadi lebih optimal dalam pengolahan data.

\section{DAFTAR PUSTAKA}

[1] Kulshreshtha, Vikas. (2011). "Benefits of Management Information System in Blood Bank", dalam International Journal Of Engineering And Science. ISSN: 2278- 4721, Vol. 1, Issue 12 (December 2012), PP 05-07. India.

[2] Pressman, Roger S. (2002). Rekayasa Perangkat Lunak Pendekatan Praktisi (Buku. Satu). Yogyakarta: Andi.

[3] Sugiyono. (2013). Metode Penelitian Kuantitatif, Kualitatif Dan R\&D (Cetakan Ke-19). Bandung: Alfabeta.

[4] Pahlevi, S. (2010). Sistem Pendukung Keputusan Pemilihan Guru Berprestasi Menggunakan Metode Analytical Hierarchy Process. Tesis S2 Ilmu Komputer UGM, Yogyakarta.

[5] M. Sidi, Mustaqbal., Firdaus, Roeri Fajri., \& Rahmadi, Hendra. (2015). "Pengujian Aplikasi Menggunakan Black Box Testing Boundary Value Analysis (Studi Kasus : Aplikasi Prediksi Kelulusan SNMPTN), dalam Jurnal Ilmiah Teknologi Informasi Terapan Volume I. No 3. 10 Agustus 2015. ISSN : 2407 - 3911. hlm.4. Diakses tanggal 18 Juli 2017. 